\title{
Experimental Study of Water Collection from Plume of an Induced-Draft Counter-Flow Cooling Tower Using Space Charge Injection
}

\author{
Md. Fahim Faisal Patwary ${ }^{1}$, Isheka Agarwala ${ }^{2}$, Rashik Ahmed ${ }^{3}$, and Dipak Kanti Das ${ }^{4}$ \\ Department of Mechanical Engineering, Military Institute of Science and Technology (MIST), Dhaka, Bangladesh \\ emails: ${ }^{*}$ fahim.mech.mist@outlook.com; ${ }^{2}$ isheka.mist@gmail.com; ${ }^{3}$ ahmed.rashik4@gmail.com; and ${ }^{4}$ dipak@mist.ac.bd
}

\section{ARTICLE INFO}

Article History:

Received: $19^{\text {th }}$ April 2020

Revised: $10^{\text {th }}$ February 2021

Accepted: 11 ${ }^{\text {th }}$ February 2021

Published: 27th June 2021

\section{Keywords:}

Space Charge

Injection Plume

Abatement Collection

Percentage Air

Ionization Liquid-Gas Ratio

\begin{abstract}
A B S T R A C T
Plume collection from cooling towers can be a reliable solution to the water scarcity problem faced in many regions around the world. Meshes are one of the most proposed collectors in this regard that rely upon inertial collision for droplet capture and are inherently limited by aerodynamics. This study quantifies the effect of electrical forces on water collection from the plume of an Induced Draft Counter Flow (IDCF) Cooling Tower by introducing sets of copper tubes at the exit of the tower. The imparting of net charge to the exhaust plume by instigating space charge directs the vapor towards the inside wall of copper tube forming water droplets. This arrangement instead of a mesh or net system, creates a lesser obstruction to flow. Fabrication of fill/packing with a corrugated wave pattern using PVC plastic demonstrates satisfactory cooling performance of the tower. An optimized $L / G$ ratio is found to exist for maximum collection efficiency of water from plume at definite entering fluid temperatures by investigating with the entering warm water temperatures at $40^{\circ} \mathrm{C}, 45^{\circ} \mathrm{C}$ and $50^{\circ} \mathrm{C}$ while the dry bulb temperature of air ranges from $23.5^{\circ} \mathrm{C}$ to $30.1^{\circ} \mathrm{C}$. The electricity consumption for this arrangement fluctuates from $2.78 \mathrm{kWh} / \mathrm{m}^{3}$ to $5.13 \mathrm{kWh} / \mathrm{m}^{3}$ for two $L / G$ ratios (23.5 and 28.3 ). Where maximum collection percentage occurs at two different entering fluid temperatures, the power expended is below the minimum used for typical desalination plants.
\end{abstract}

(C) 2021 MIJST. All rights reserved.

\section{INTRODUCTION}

The cooling tower is equipment most widely used to release excess heat loads from various processes, such as thermal and nuclear power plants, electric power generation units, refrigeration and air-conditioning systems, chemical and petroleum industries, into the atmosphere (Wakil, 1985). Transfer of mass and thermal energy from high-temperature water to coolant air is the basis on which this device operates. In wet cooling towers, a direct interface between coolant air flow and warm water is created as water flows over the fill. As this hot water gets cooled down, a portion of it evaporates and leaves the tower along with the air. So, air's temperature is raised and its relative humidity elevates to $100 \%$ causing a vapor fog to escape out otherwise known as plume. While maximum performance is the aim of every cooling system, visible water vapor plumes might be the unexpected result of certain environmental conditions. These plumes have reportedly exerted negative effects on the environment by affecting clarity of view and safety as well as public insight, and decisively delaying permits and jeopardizing project timelines.

In Mechanical-Draft Cooling Towers (MDCT) there have been incidences of fogging at ground level along with icing typically in winter. The updrafts from MDCT have contributed to the formation of cloud. Light snow has also been observed due to this dissipation which was first recorded in 1975 (Carson, 1980). Other effects include possible contribution to severe weather such as thunderstorms, hail and tornadoes along with precipitation generation (Huff et al., 1971). In areas with frequent fog, visibility problems are caused by the descent of this condensing vapor plume. There have also been instances of toxic component formation due to mixture of plume with gaseous emissions of the industry. For example, formation of sulphurous acid mist due to reaction with sulphurdioxide gases. Supersaturated region created, when the ambient temperature goes below $10-16^{\circ} \mathrm{C}$ and the relative 
humidity exceeds $80 \%$, is also one of its effects. As a result there have been several researches for dispensing this plume coming out of the towers. One of these processes is adding heat to the tower exhaust thus superheating the plume. The installation and operating cost estimated for this process is $\$ 40,000$ and $\$ 16,000$ annually. Discarding the process latent heat without evaporation by altering the cooling method is also one of the processes of plume abatement. Installation and operation cost estimated for the system in practice of this method is $\$ 22,000$ and $\$ 3,000$ annually respectively (Veldhuizen \& Ledbetter, 1971).

Researchers from MIT (USA) came up with a new approach for fog harvesting mesh in 2018 in which they introduced electrical forces, and aerodynamic drag forces could be overcome by dint of it (Damak \& Varanasi, 2018). They measured collection efficiency of fog on single-wires, and meshes and proposed a physical model to quantify it (Damak \& Varanasi, 2018). In this paper, a non-identical setup for water collection from the plumes of cooling tower has been proposed, inspired by the principles of electrostatic precipitators (Parker, 2003; Kraemer \& Johnstone, 1955; Uchiyama \& Jyumonji, 1995). Small copper tubes serve as collectors inside of which there are smaller copper tubes that serve as emitters. Plume is directed to pass in between these tubes while the tubes are maintained at a high voltage of $\sim-7 \mathrm{kV}$. Thus, it induces a net charge into the plume droplets and directs them towards the collector. The electric field lines take off from emitter and end at grounded collector. When the electric forces surpass the air drag forces, the droplets travel along the field lines and deposit on the inside wall of collector tube.

Based on prior studies, the main factor influencing the efficiency of a cooling tower is the thermal performance inside the filling zone. This is because $70 \%$ of the heat dissipating capacity is based on the filling zone (Williamson et al., 2008). An IDCF cooling tower prototype of the size constructed for this study would produce plume with an inadequate concentration of water. So, instead of straight or zigzag shapes, fill material is used in waveforms for the occurrence of highest possible heat rejection so as to obtain more concentrated plumes (Novianarenti et al., 2019). The primary objective of this experiment is to reduce the water content in the exhaust plume of cooling towers, collect it instead for reuse and hence, diminish some of the harmful effects caused by them. The results from this study have shown that this can simultaneously reduce the current reverse de-salination energy consumption $\left(\sim 3\right.$ to $\left.5 \mathrm{kWh} / \mathrm{m}^{3}\right)$ required for makeup water of cooling towers in power plants by an estimated energy consumption of $\sim 0.2 \mathrm{kWh} / \mathrm{m}^{3}$ for more concentrated plumes which is on the order of 5000 litres $/ \mathrm{m}^{2}$ per day. It has also been shown that the collection percentage from the evaporative loss is variable depending upon various conditions and specific criteria in this paper.

\section{BRIEF THEORETICAL BACKGROUND}

During the ionization of air, the dielectrophoretic nucleation of polar water molecules on ions allows for 16-20\% dehumidification (Reznikov, 2003; Reznikov,
2014). However, the electrostatic enhancement of condensation occurs due to the amalgam of three phenomena:

1. the dielectrophoretic (DEP) nucleation of the vapor on electrically charged centres;

2. the electrohydrodynamic (EHD) flow of the vapor as electrically charged droplets create drag; and

3. the temporal (until droplets are discharged) storage of heat energy in electrically charged droplets.

The stability of small droplets is notably affected only by the dielectrophoretic potential. The total latent heat of evaporation is relatively small for small droplets $(<10 \mu \mathrm{m})$ which is shown in Figure 1 (Reznikov, 2015). At a constant droplet volume of $4 \pi R^{3} / 3$ where $R$ is the radius of a drop, the heat capacitance is proportional to the second derivative of Gibbs energy, $\mathrm{G}=N \times \mu_{l}$, where $N$ is the number of molecules contained in the cluster (droplet), and $\mu_{l}$ is the liquid chemical potential.

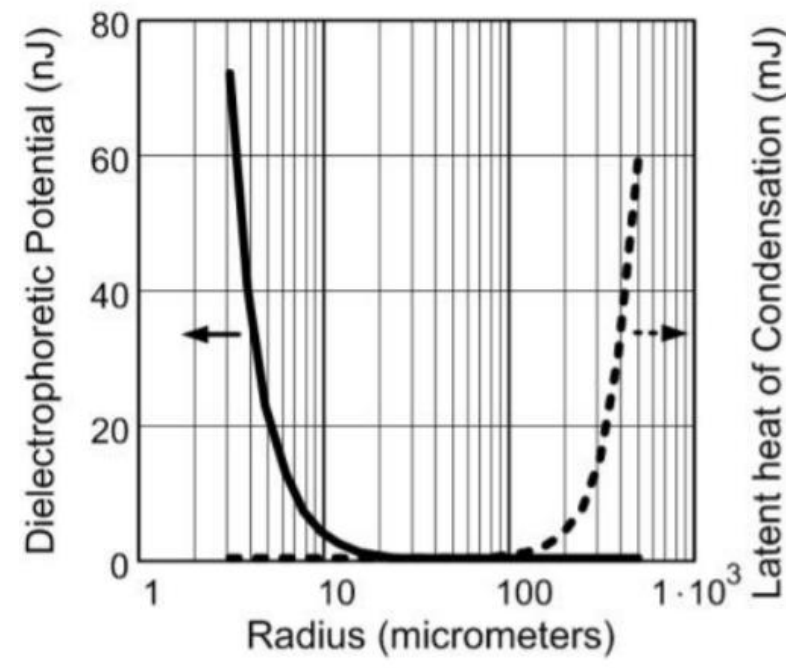

Figure 1: Droplet DEP potential (solid line) contrasted with its latent heat of condensation (dotted line)

Therefore, the isochoric heat capacitance of the droplet is stated as

$$
\mathrm{C}_{\mathrm{V}, \mathrm{N}}=-\mathrm{T}\left(\frac{\partial^{2} \mathbf{G}}{\partial \mathrm{T}^{2}}\right)_{\mathrm{V}, \mathrm{N}}=-\mathrm{T} \cdot \mathrm{N}\left(\frac{\partial^{2}\left(\mu_{\mathrm{n}}-\Delta \mu_{\mathrm{DEP}}\right.}{\partial \mathrm{T}^{2}}\right)_{\mathrm{V}}
$$

where $\mu_{n}$ is the chemical potential in the neutral droplet and $\triangle \mu_{D E P}$ is the decrement of chemical potential due to dielectrophoretic forces.

$$
\Delta \mu_{\mathrm{DEP}}=\frac{\mathrm{q}^{2} \mathrm{v}^{\mathrm{l}}}{32 \pi^{2} \varepsilon_{0} \mathrm{R}^{4}}+\frac{\mathrm{q} \rho_{0}}{4 \pi \varepsilon_{0} \mathrm{R}^{2}}
$$

Here, $q$ represents a single electron charge, equal to $1.6 \times 10^{-19} \mathrm{C}$ and $v_{l}$ is the volume per single molecule in liquid. Therefore, the heat capacitance of the droplet should decrease due to the electric charge. Experimental data from Sundén et al. (2009) supports this conjectural conclusion. There are more aiding factors supported by numerical modelling and experimental data from $\mathrm{Yu}$ (2005) where it shows that same number of molecules in bulk neutral water contains higher enthalpy in charged droplet form and the excess enthalpy is added as energy in the form of electric polarization. 
A decrease in temperature of the droplet at the discharge on the ground condensing wall is induced by the decrement of heat capacitance of the electrically charged droplet. The latent heat of condensation decreases relatively and it is also partially replaced by electrostatic energy which ultimately results in the condensation of droplets on the wall.

\section{EXPERIMENTAL PROCESS}

\section{A. Experimental Setup}

The cooling tower used in this experiment is an induced draft counter flow wet type with a circular cross-section. The installation is done on a steel frame and is accompanied by the following.

- A collection basin for collecting cooled water.

- A hot water reservoir with arrangement for electric heaters to heat up the water.

- A water pump at the bottom to pump from reservoir with a water distribution system up to the top containing spraying nozzles. Heated water is sprayed through nozzles that flows down through the fill to the basin and continues the cycle.

- A draft fan for inducing airflow from the bottom to cool down hot water. This air, rich in water vapor, exits from the top of the tower increasing the air temperature.

The setup is shown schematically and photographically in Figure 2 and Figure 3, respectively.

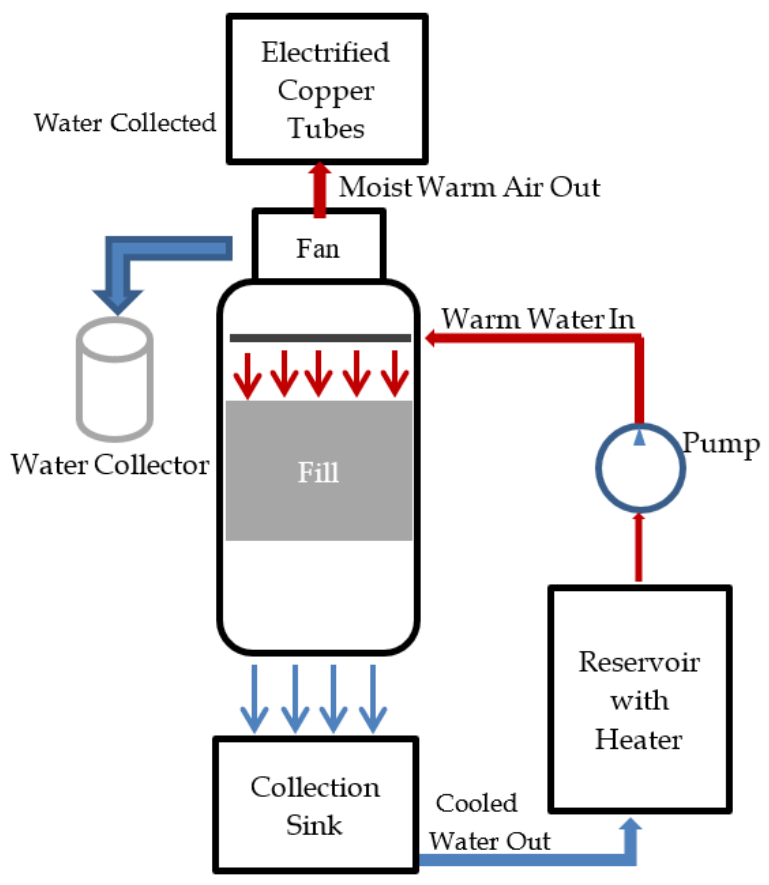

Figure 2: Schematic diagram of the experimental setup

A unique arrangement is built for inducing space charge to the exiting air. This arrangement consists of the following parts.

- A right-angled U-shaped passage tube for turning the flow $180^{\circ}$ towards gravity. One end of this tube is attached to the exhaust side of the fan while the other end is made such that the exiting air flows through four holes.

- Four cylindrical copper tubes are fixed under these holes with another four smaller tubes inside.

- Electric wiring of copper tubes with D.C. voltage boosters.

- A collector for the condensed water from inside the copper tubes.

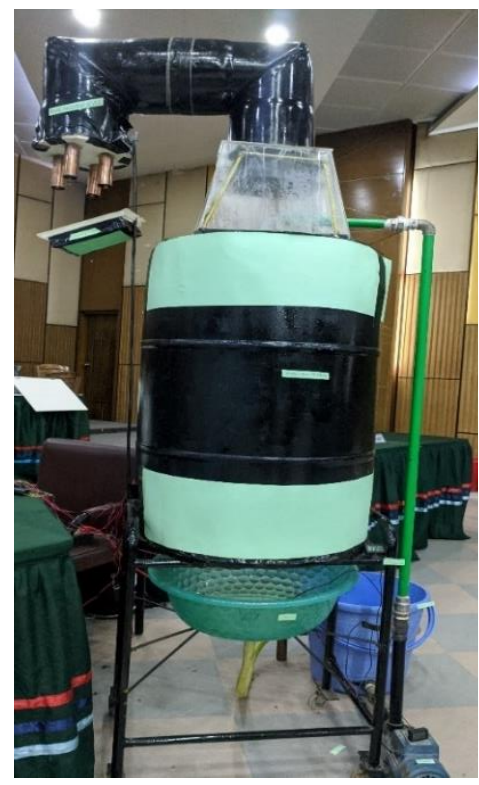

Figure 3: Photograph of the experimental setup

A screenshot of the view from the bottom of the water collection system designed in SolidWorks is given in Figure 4. Figure 5 is an image of the actual constructed water collection system. Figure 6 shows a close-up view of the electrified copper tubes, while Figure 7 displays the cross-section of a single pair of copper tubes. The annular space between the inner and outer copper tube is where corona discharge occurs.

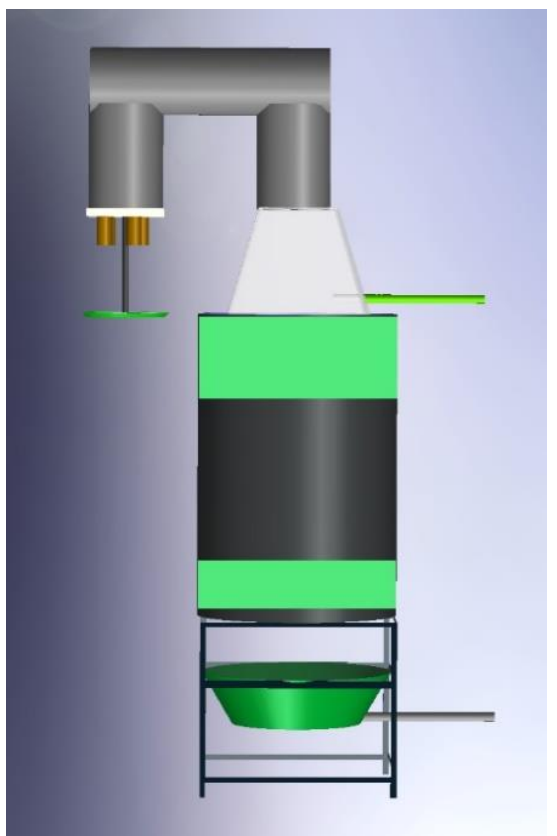

Figure 4: SolidWorks design of water collection system 


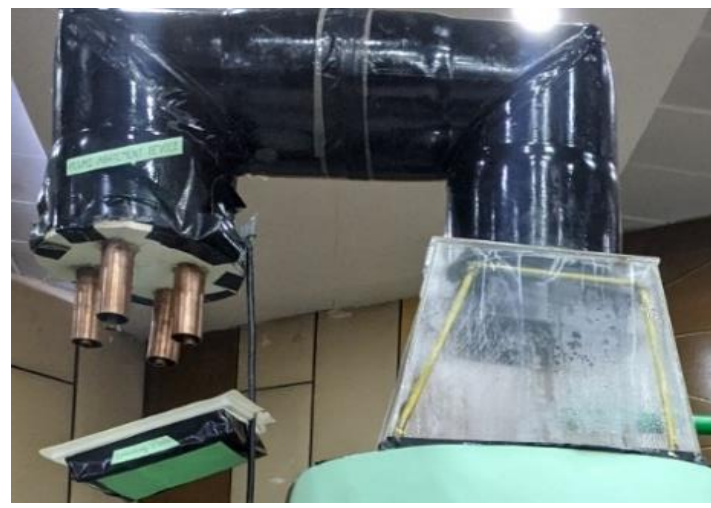

Figure 5: Photograph of water collection system.

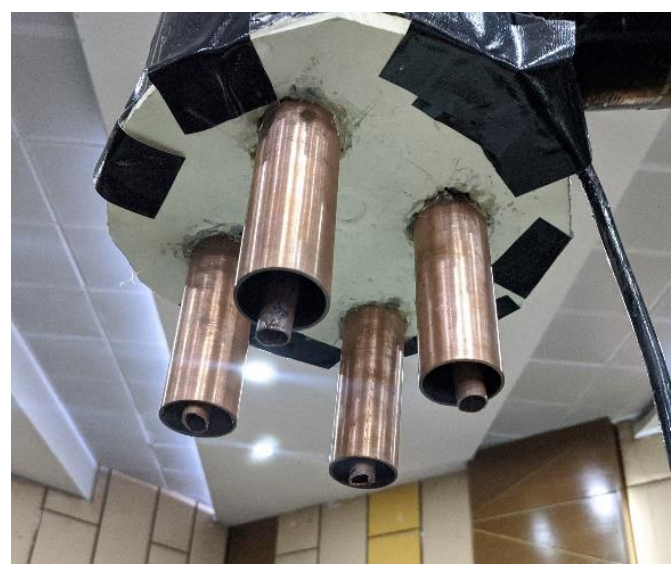

Figure 6: Picture showing spaces inside copper tubes for charge injection

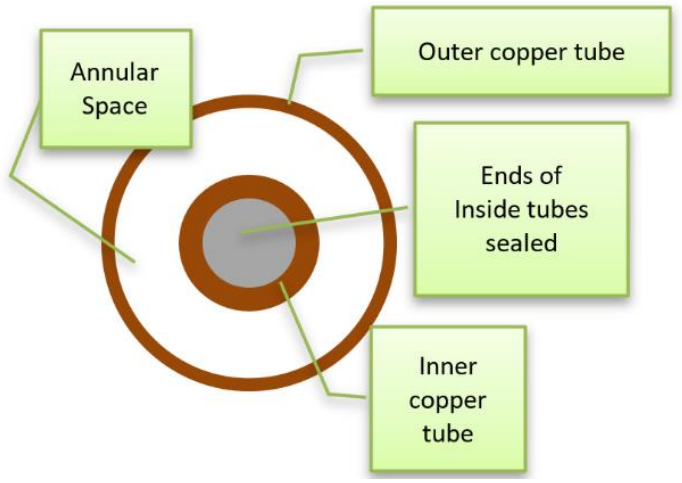

Figure 7: A cross-sectional view of one set of copper tubes

\section{B. Equipment and Parameters}

The equipment used in this experiment and their respective specifications are listed in Table 1 . The parameters to be monitored and the measuring instrument for each are illustrated in Table 2.

Table 1

Equipment and Specifications

\begin{tabular}{ll}
\hline \hline Equipment Used & Specification \\
\hline Pump & Max head: $40 \mathrm{~m}$ \\
Max flow rate: $40 \mathrm{~L} / \mathrm{min}$ \\
Induced Draft Fan & Air velocity: $1.5 \mathrm{~m} / \mathrm{s}$ \\
Electric Heater & Power: $500 \mathrm{~W}$ \\
High Voltage Generator & Input: DC $3-6 \mathrm{~V} ;$ output: $10 \mathrm{kV}$ \\
\hline \hline
\end{tabular}

Table 2

Monitor parameters and Measurement instruments

\begin{tabular}{ll}
\hline \hline Parameters & Measuring Instrument \\
\hline $\begin{array}{l}\text { Inlet dry and wet bulb } \\
\text { temperatures }\left({ }^{\circ} \mathrm{C}\right)\end{array}$ & Alcohol Thermometer \\
$\begin{array}{l}\text { Outlet air temperature }\left({ }^{\circ} \mathrm{C}\right) \\
\begin{array}{l}\text { Inlet and outlet water } \\
\text { temperatures }\left({ }^{\circ} \mathrm{C}\right)\end{array}\end{array}$ & Alcohol Thermometer \\
$\begin{array}{l}\text { Air flow velocity }(\mathrm{m} / \mathrm{s}) \\
\text { Volume of water collected } \\
(\mathrm{m} 3)\end{array}$ & Digital Thermocouple \\
\hline \hline
\end{tabular}

\section{Water Collection Mechanism}

Sets of two copper tubes of uniform thickness $(\sim 1 \mathrm{~mm})$ with different diameters are used as the opposing electrodes for space charge injection. $13 \mathrm{~mm}$ tubes with the ends sealed are placed axially along the centre of hollow $32 \mathrm{~mm}$ tubes. The plume from the cooling tower outlet is allowed to pass through the space between the copper tubes. The high voltage is generated using D.C. voltage boosters, where each booster is given an input of 3-6 $\mathrm{V}$ and produces an output of 7-10 kV. Corona discharge between the copper electrodes is observed at about $7 \mathrm{kV}$. The electric field produced causes the particles in the air and water mixture passing through the space between the electrodes to become ionized. The ionized water vapor particles deflect inside the field as shown in Figure 8. Upon contact with the surface of the electrodes, the vapor gives off latent heat of vaporization and condenses to liquid water.

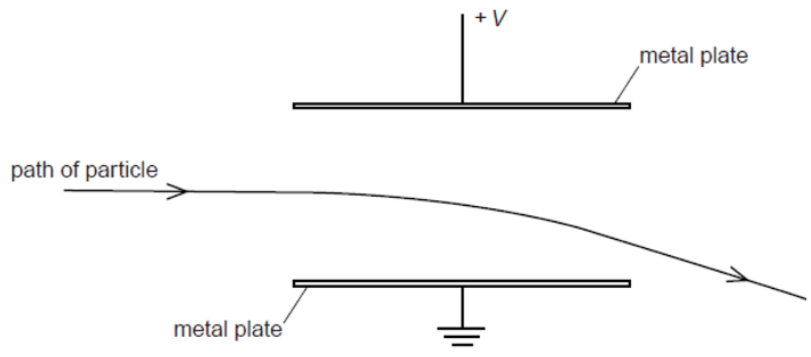

Figure 8: Movement of a particle inside an electric field

\section{Experimental Procedure}

The experiment is carried out at four different flow rates and using three different inlet warm water temperatures for each. So, 12 cases are developed for this paper based on different pairings of mass flow rate of water and warm water temperature. Cooled water temperature, hot air out temperature, amount of collected water and environmental dry bulb and wet bulb temperatures are read from alcohol thermometers and digital thermocouple with $\pm 1{ }^{\circ} \mathrm{C}$ accuracy. The cases are noted in Table 3.

Flow rate of water is controlled using a manually operated flow control valve. Inlet temperature of water was maintained using electric heaters. The U-shaped circular duct with two $90^{\circ}$ elbows is used to direct the plume to the copper tubes so that the final output air flows vertically downwards. This was done to facilitate the movement of 
condensed water droplets formed in the copper tubes so that air did not flow against them. This can be visualized in Figure 4 and in Figure 7.

Table 3

Tower Operating Parameters

\begin{tabular}{|c|c|c|c|c|c|}
\hline $\begin{array}{c}\mathrm{T}_{1} \\
\left({ }^{\circ} \mathrm{C}\right)\end{array}$ & 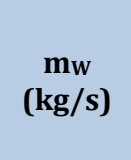 & $\begin{array}{c}\mathrm{T}_{2} \\
\left({ }^{\circ} \mathrm{C}\right)\end{array}$ & $\begin{array}{l}\mathrm{T}_{\mathrm{a} 1} \\
\left({ }^{\circ} \mathrm{C}\right)\end{array}$ & $\begin{array}{c}T_{\mathrm{f} 1} \\
\left({ }^{\circ} \mathrm{C}\right)\end{array}$ & $\begin{array}{c}\text { Air (Plume) } \\
\text { Temperature } \\
\text { at Tower } \\
\text { Outlet }\left({ }^{\circ} \mathrm{C} \text { ) }\right.\end{array}$ \\
\hline \multirow{4}{*}{40} & 0.047833 & 37.2 & 23.5 & 22.8 & 26 \\
\hline & 0.088467 & 38.2 & 24 & 23.5 & 27.5 \\
\hline & 0.106567 & 37.9 & 24 & 23.5 & 26.2 \\
\hline & 0.1451 & 38.7 & 28.9 & 27.5 & 32.5 \\
\hline \multirow{4}{*}{45} & 0.047833 & 41.5 & 29.5 & 25.5 & 32 \\
\hline & 0.088467 & 41.9 & 24 & 23.5 & 28 \\
\hline & 0.106567 & 40.9 & 24 & 23.5 & 26.4 \\
\hline & 0.1451 & 42.9 & 30.1 & 25.5 & 33 \\
\hline \multirow{4}{*}{50} & 0.047833 & 45.3 & 29.5 & 25.5 & 32 \\
\hline & 0.088467 & 45.7 & 24 & 23.5 & 28.1 \\
\hline & 0.106567 & 44 & 24 & 23.5 & 26.7 \\
\hline & 0.1451 & 46.8 & 30.1 & 25.5 & 33 \\
\hline
\end{tabular}

\section{NOMENCLATURES}

a Approach, ${ }^{\circ} \mathrm{C}$

$C_{r} \quad$ Water Circulation rate

$m_{l} \quad$ Air mass flow rate $(\mathrm{kg} / \mathrm{s})$

$M_{w} \quad$ Water loss $(\mathrm{kg} / \mathrm{s})$

$m_{w} \quad$ Water mass flow rate $(\mathrm{kg} / \mathrm{s})$

$T_{l} \quad$ Entering warm water temperature of the tower, ${ }^{\circ} \mathrm{C}$

$T_{2} \quad$ Cold water temperature at the cooling tower outlet, ${ }^{\circ} \mathrm{C}$

$T_{a l} \quad$ Inlet air dry bulb temperature, ${ }^{\circ} \mathrm{C}$

$T_{d} \quad$ Temperature difference between hot water in, $T_{l}$ and cold air in, $T_{a l},{ }^{\circ} \mathrm{C}$

$T_{f 1} \quad$ Wet bulb temperature at tower inlet, ${ }^{\circ} \mathrm{C}$

$V_{l} \quad$ Air specific volume at tower inlet $\left(\mathrm{m}^{3} / \mathrm{kg}\right)$

$X_{2} \quad$ Humidity ratio at tower outlet ( $\mathrm{kg}$ water $/ \mathrm{kg}$ dry air)

$X_{I} \quad$ Humidity ratio at tower inlet $(\mathrm{kg}$ water $/ \mathrm{kg}$ dry air)

Z Cooling range, ${ }^{\circ} \mathrm{C}$

$\mu \quad$ Cooling coefficient, $\%$

\section{METHODOLOGY}

The first practical theory and equation set for the performance evaluation of cooling towers developed by Merkel has been widely employed ever since 1925 and is used in Liao et al. (2019). However, evaporative water losses are not considered in this model (González Pedraza et al., 2018). This evaporation loss as found by a numerical study conducted on cross flow cooling towers accounts for up to $5.1 \%$ of the total inlet water (Bourouni et al., 2008).
This percentage is not negligible at all and hence, many models have been proposed to calculate the loss of water by evaporation using the empirical relation of evaporative water loss (Perry \& Green, 1997)

Evaporation loss $=0.00085 \times 1.8 \times \mathrm{C}_{\mathrm{r}} \times\left(\mathrm{T}_{1}-\mathrm{T}_{2}\right)$

This study has followed the approach of evaporative water loss equation deduced from the above empirical equation recently by Naik \& Muthukumar (2017) that has later been used by Shublaq \& Sleiti (2020) and Saber \& Maree (2019). For the evaluation of the experimental setup as a regular working IDCF cooling tower, necessary performance parameters of a cooling tower according to (Saber \& Maree, 2019, pp. 1-8) are stated below.

The difference in temperature between the hot water entering the tower and the cold water exiting the tower is the cooling range.

$\mathrm{Z}=\mathrm{T}_{1}-\mathrm{T}_{2}$

The difference in temperature of the cold water exiting the tower and the wet bulb temperature of the air is known as the approach.

$\mathrm{a}=\mathrm{T}_{2}-\mathrm{T}_{\mathrm{f} 1}$

The cooling coefficient is the efficiency of a cooling tower and is given by

$\mu=\frac{T_{1}-T_{2}}{T_{1}-T_{1} 1}$

Effectiveness of a cooling tower is given by

$\varepsilon=\frac{T_{1}-T_{2}}{T_{1}-T_{a 1}}$

These parameters are plotted versus four different flow rates of water $(0.047833 \mathrm{~kg} / \mathrm{s}, 0.088467 \mathrm{~kg} / \mathrm{s}, 0.106567$ $\mathrm{kg} / \mathrm{s}, 0.1451 \mathrm{~kg} / \mathrm{s}$ ) with separate curves for each of the warm water temperatures $\left(40^{\circ} \mathrm{C}, 45^{\circ} \mathrm{C}\right.$ and $\left.50^{\circ} \mathrm{C}\right)$.

A certain amount of water is lost due to evaporation in a cooling tower with an open circuit and equals to the amount of makeup water required. This water loss is given by

$\mathrm{M}_{\mathrm{w}}=\left(\mathrm{X}_{2}-\mathrm{X}_{1}\right) \times \mathrm{m}_{\mathrm{l}}$

Mass flow rate of air through the tower is given by

$\mathrm{m}_{\mathrm{l}}=$ density $\times$ flow area $\times$ air speed

Specific density of dry air is measured at the air outlet conditions and air speed is measured at outlet of copper tubes by anemometer.

Liquid Gas Ratio is the ratio of the mass flow rate of water to that of air.

$\mathrm{L} / \mathrm{G}$ ratio $=\frac{\mathrm{m}_{\mathrm{w}}}{\mathrm{m}_{1}}$

Temperature difference between entering warm water and inlet cold air,

$\mathrm{T}_{\mathrm{d}}=\mathrm{T}_{1}-\mathrm{T}_{\mathrm{a} 1}$

The percentage of collection, or collection efficiency, is measured with respect to $M_{w}$ for each of the cases. 
Collection $\%=$ collected water $\times 100 / \mathrm{M}_{\mathrm{w}}$

For understanding the nature of collection efficiency two graphs are shown in the following ways.

i) Collection \% vs Temperature difference between entering warm water and entering cold air, $T_{d}$. The points in the graph are marked for the corresponding $L / G$ ratios.

ii) Collection \% vs $L / G$ ratio with separate curves drawn for each of the warm water temperatures.

The electrical energy consumption for each of the 12 cases has been plotted against the corresponding collection efficiencies. Separate curves are drawn for each of the $L / G$ ratios.

\section{RESULTS AND DISCUSSION}

The variation of cooling range with water mass flow rate shown in Figure 9 demonstrates that the cooling range decreases with increasing mass flow rate of water. This is because the amount of heat transfer is dependent on the two mass flow rates. In the case of a large quantity of air that is in contact with a low quantity of water, the result is a larger degree of water cooling. Thus, cooling range is high, but in the case of a larger quantity of water that is in contact with less quantity of air, the result is a lesser degree of water cooling and so cooling range is low. For all cases the cooling range increases with increasing warm water in temperature, $T_{l}$ and the best cooling range is obtained for $50^{\circ} \mathrm{C}$ at the lowest flow rate $(0.047833 \mathrm{~kg} / \mathrm{s})$.

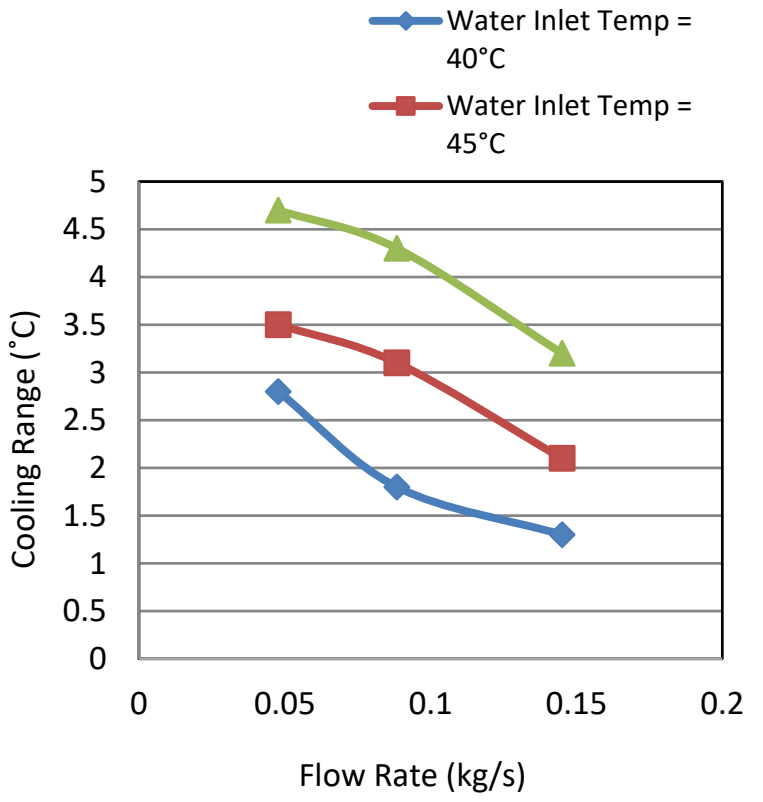

Figure 9: Cooling Range as a function of Flow Rate

Figure 10 illustrates the variation of the approach with water mass flow rate. It shows that the approach is maximum at moderate water flow rates and does not gradually increase with increasing flow rate. A decrease in the corresponding wet bulb temperature reduces the coldwater temperature. The approach increases with increasing warm water temperature and the minimum approach is obtained for $40^{\circ} \mathrm{C}$ at the highest flow rate $(0.1451 \mathrm{~kg} / \mathrm{s})$.

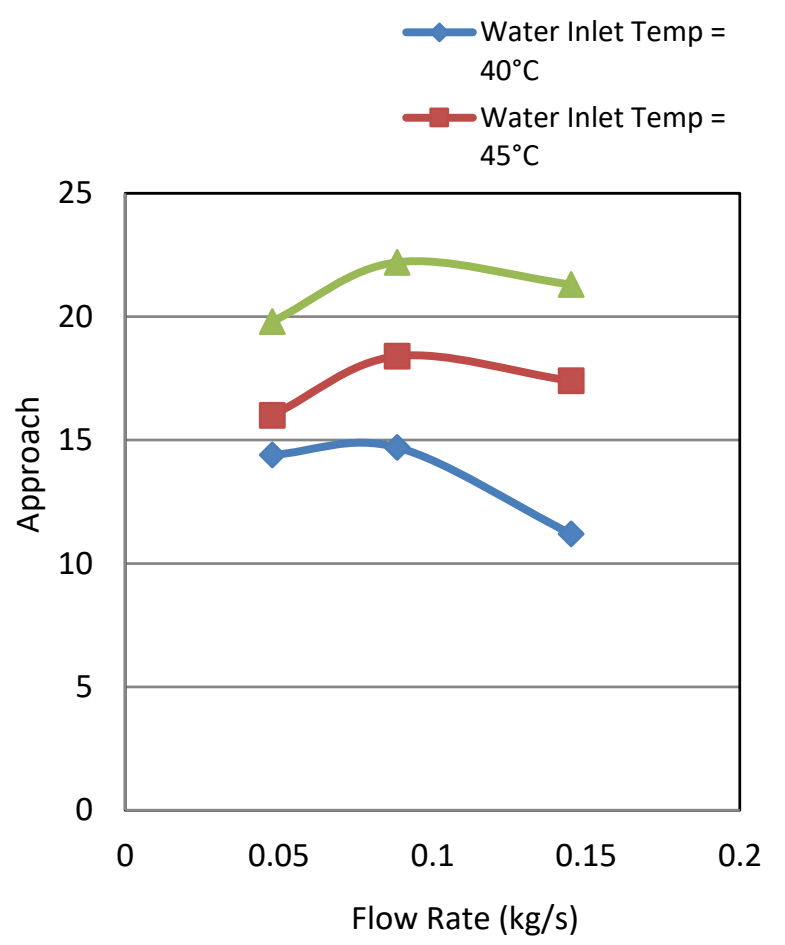

Figure 10: Approach as a function of Flow Rate

The effectiveness decreases with increasing water mass flow rate as shown in Figure 11, and it increases with increasing warm water temperature. The best cooling tower effectiveness is obtained for both $45^{\circ} \mathrm{C} \& 50^{\circ} \mathrm{C}$ at the lowest flow rate $(0.047833 \mathrm{~kg} / \mathrm{s})$.

The cooling coefficient decreases with increasing water mass flow rate as shown in Figure 12. This implies that cooling coefficient is directly proportional to cooling range. Also, the cooling coefficient increases with increasing warm water temperature and the best cooling coefficient is obtained for $50^{\circ} \mathrm{C}$ at the lowest flow rate $(0.047833 \mathrm{~kg} / \mathrm{s})$.

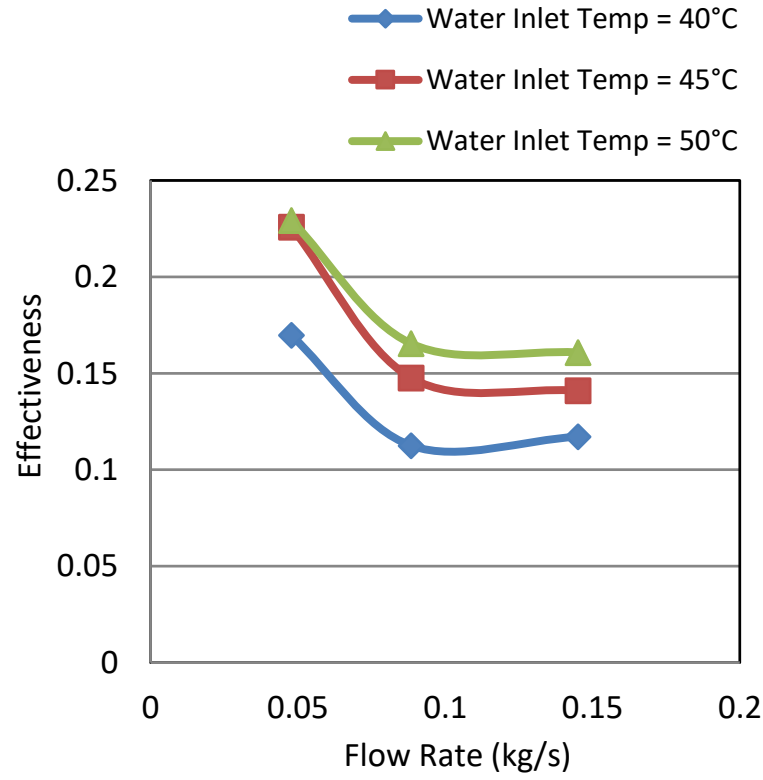

Figure 11: Effectiveness as a function of Flow Rate 


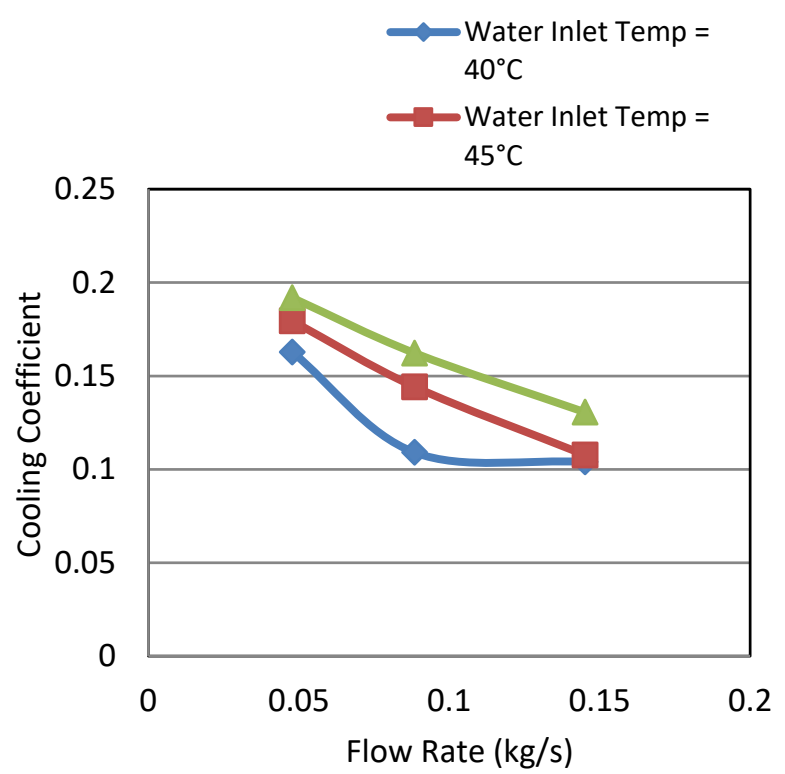

Figure 12: Cooling Coefficient as a function of Flow Rate

The aforementioned figures and their discussion are given to justify our setup as a regular working cooling tower (used mostly in refrigeration and air conditioning sectors). The similarity with the curves from (Saber \& Maree, 2019, pp. 1-8) substantiates the validation of the prototype and the addition of a flow-obstructive setup at the outlet of the tower does not affect the relation of cooling effect at any warm water temperatures. The following discussion upholds the distinctive studies from our setup.

The optimum counter flow rates of water and air account for maximum cooling efficiency (cooling coefficient) at definite inlet temperatures. Figure 13 shows that the cooling efficiency decreases with rising value of $L / G$ ratio, which is in accordance with Figure 12.

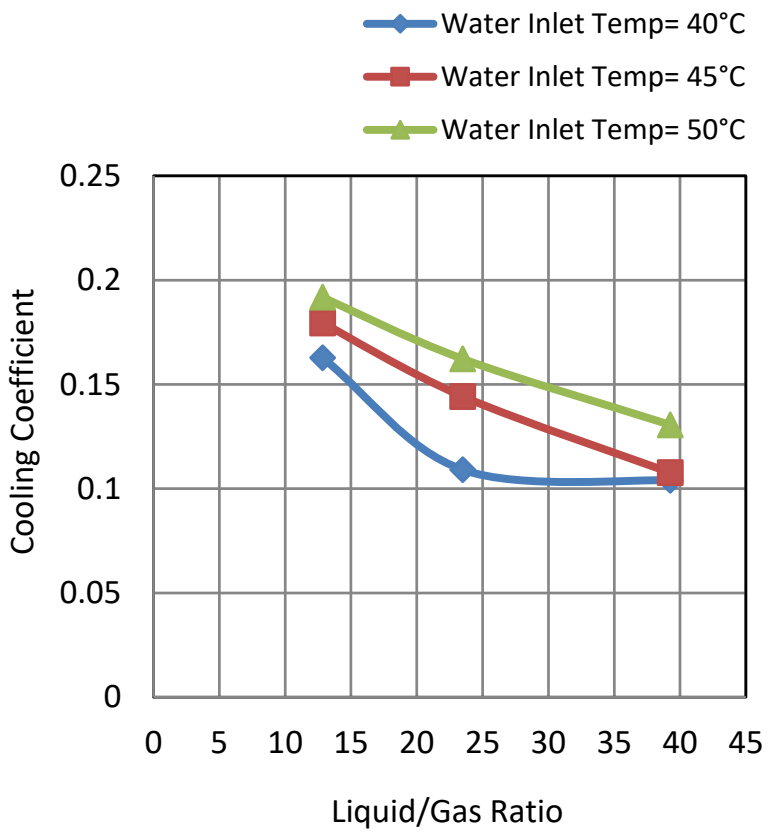

Figure 13: Cooling Coefficient as a function of $L / G$ ratio

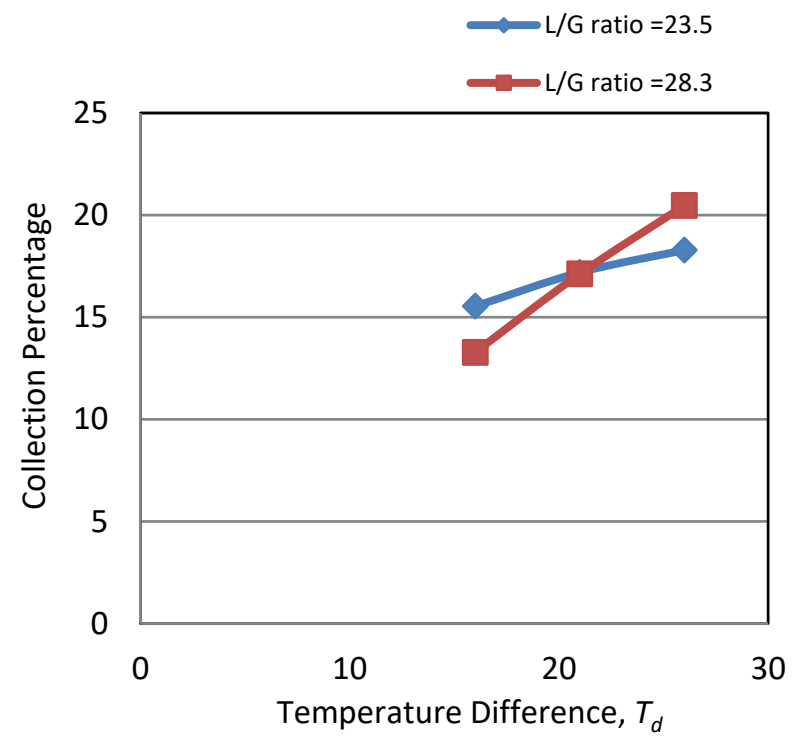

Figure 14: Collection percentage as a function of Temperature difference, $T_{d}$ for different $L / G$ ratios

Figure 14 displays the nature of variation in collection percentages with respect to the temperature difference between the inlet temperatures of the two fluids for two $L / G$ ratios (23.5 and 28.3). The curves exemplify a linear relation for these $L / G$ ratios.
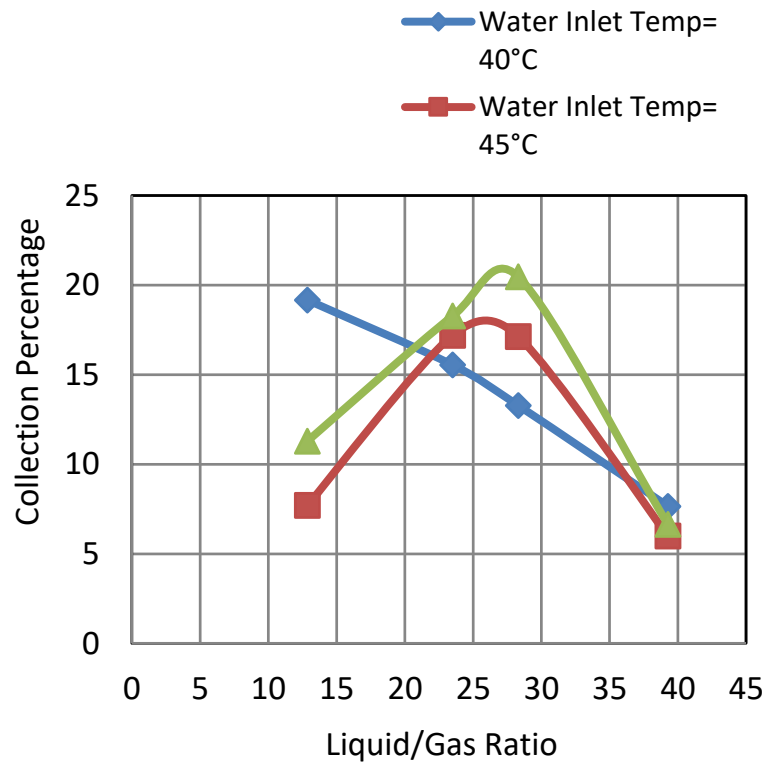

Figure 15: Collection percentage as a function of $L / G$ ratio.

Figure 15 illustrates the previously stated fact for the existence of an optimum value of $L / G$ ratio which in this case is for maximum collection percentage for any hot water in temperature, $T_{l}$. The curves maintain a certain peak value of collection efficiency for higher warm water temperatures, before and after which the value decreases. At the lowest warm temperature, a continuous fall of collection percentage with increasing $L / G$ ratios is observed. This could suggest that the peak for this curve is towards the left of the graph. The maximum percentage of collection is observed for $L / G$ ratio of $27-28$ at hot water inlet temperature of $50^{\circ} \mathrm{C}$. 


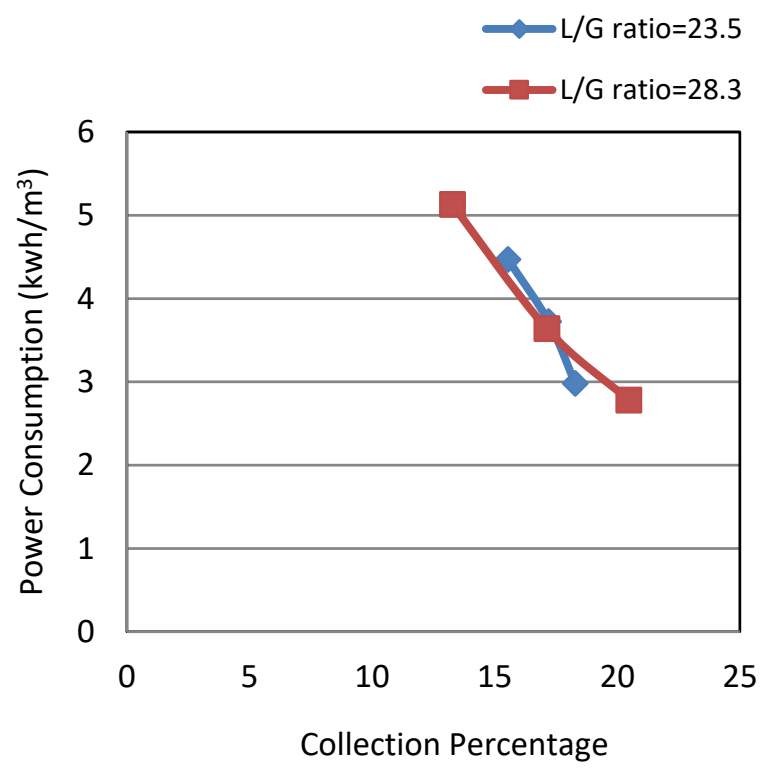

Figure 16: Power consumption as a function of Collection percentage for different $L / G$ ratios.

Figure 16 displays the ranges of electricity consumption with respect to the collection efficiency for two $L / G$ ratios. The highest electricity consumption is found to be 5.13 $\mathrm{kWh} / \mathrm{m}^{3}$ and the lowest to be $2.78 \mathrm{kWh} / \mathrm{m}^{3}$. Notably, the lowest power consumption corresponds to the maximum collection percentage $(\sim 20 \%)$ for the curve of $L / G$ ratio 28.3. $L / G$ ratios signify the variation of vapor density and so, the trait of the curves varies due to variation in plume density. The maximum collection efficiencies for the two curves consume below $3 \mathrm{kWh} / \mathrm{m}^{3}$ and offer the possibility of more sets of operating conditions below that. Furthermore, this energy consumption can be minimized significantly for high density plumes that come out of commercial cooling towers.

Figures 14-16 are the original works of this paper which assist in finding out the optimum operating condition required to achieve best collection efficiency of water from the plume keeping the properties of an IDCF tower unhindered. Figure 14 brings out an important fact that the collection efficiencies increase with increasing temperature difference. Additionally, Figure 15 proves that the peak values of collection efficiencies exist at moderate $L / G$ ratios (27-28) for the higher warm water temperatures. Figure 16 marks out that $L / G$ ratios that are close to these moderate values, being the best operating condition for the tower, can also correspond to a relatively low consumption of power. De-salination plants consume at-least $3 \mathrm{kWh} / \mathrm{m}^{3}$ (Damak \& Varanasi, 2018), and it has been found that more than one cases in our setup consume less than this value.

If optimum conditions for maximum collection efficiency are not prioritized, there are more findings to look for in these figures. Figure 14 indicates that the maximum collection percentage almost corresponds to the maximum temperature difference for higher $L / G$ ratios. So, the cooling effect and thus, evaporative loss may be least but only the highest temperature difference, $T_{d}$ will get back maximum water from the plume coming out of the cooling tower. On the other hand, it is evident from Figure 15 that the collection efficiency for any $L / G$ ratio at higher warm water temperatures increases with increasing warm water temperature. Thus, for any fixed $L / G$ ratio, these two figures represent a dependency of collection efficiency on two factors, the temperature difference of the inlet fluids and the inlet warm water temperature. This paper evaluates the necessity of finding the relative significance of these two factors on collection efficiency.

Maximum ionization rate ensures highest collection efficiency and depends on exiting velocity, density and temperature of the plume. Plume temperature depends on the heat transfer between water and air, i.e. entering fluid temperatures. At fixed conditions of entering fluid temperatures, a definite value of $L / G$ ratio gives out a definite evaporative cooling thus, a definite density of plume as shown in Figure 13. The exiting velocity is constant for all the cases in this study and so, an optimum density must exist for maximum collection efficiency at definite entering fluid temperatures. In most of the cases, Figure 14 shows a subsisting linear relation of collection \% with $T_{d}$ and Figure 15 maintains a bell curve signifying an optimum $L / G$ ratio for the peak value. The methods are to be studied on other types and sizes of cooling towers in order to find more relevancy in these findings. Overall, the installation of a duct and tube structure on top of cooling towers instead of the mesh system proposed by MIT (Damak \& Varanasi, 2018) unlocked yet another effective way of water collection from the plume expelled by the towers. Based on the results, this new approach of water collection can be successfully implemented in cooling towers.

\section{CONCLUSIONS}

Any technology that incorporates the generation or saving of usable water in an energy-efficient manner is required for stepping into a sustainable future. The loss of water in cooling towers is what we intend to minimize in order to reduce the harmful effects of plume with a low consumption of electricity. The cooling tower built for this experiment represents an ideal prototype (3:1) of those being utilized in the commercial refrigeration or other industrial sectors. The main conclusive findings of this study are-

1. Introducing a properly designed flow-obstructive structure on top of the tower does not constrain the cooling effect of the tower.

2. The water collection efficiency relies on $L / G$ ratio and inlet fluid temperatures in most of the cases. The best collection efficiency is obtained for a condition of warm water entering the tower at $50^{\circ} \mathrm{C}$ maintaining a $L / G$ ratio of 28.3 . This condition is experimented at dry and wet bulb temperatures of $24^{\circ} \mathrm{C}$ and $23.5^{\circ} \mathrm{C}$ respectively and remarkably uses up the lowest electric energy of about $2.78 \mathrm{kWh} / \mathrm{m} 3$.

3. Most importantly, two optimum operating conditions at different sets of entering fluid temperatures are found in this study which consume lower energy compared to the minimum energy used in de- 
salination plants $(3 \mathrm{kWh} / \mathrm{m} 3)$ and thus the proposed system can be promisingly eco-friendly as well as cost effective.

\section{RECOMMENDATIONS}

There is a potential chance of improved collection efficiency with cooling towers of better performance and higher water content in the plume. Designing a curved Ushaped passage instead of $90^{\circ}$ bends may offer a lesser hindrance for air flow raising the cooling performance of a cooling tower.

Improved mechanism for air ionization to enhance the collection of water can be studied by

- Varying the space between the electrodes.

- Varying the relative position of electrodes (emitter being held slightly above the collector).

- Varying the overall geometry of copper tubes (spiral, curve, funnel shapes).

- Integrating an edgy, slotted, perforated, wavy, or a combination of designs inside the copper tube

- Using a new metal or alloy instead of copper (aluminium, nickel or alloys)

\section{ACKNOWLEDGEMENTS}

This work was supported by the Department of Mechanical Engineering (ME), Military Institute of Science and Technology (MIST), Dhaka, Bangladesh.

\section{REFERENCES}

Bourouni, K., Bassem, M. M., \& Chaïbi, M. T. (2008). Numerical study of coupled heat and mass transfer in geothermal water cooling tower. Energy Conversion and Management, 49(5),

988-994. DOI:10.1016/j.enconman.2007.10.003

Carson, J. E. (1980). The Atmospheric Impacts of Evaporative Cooling Systems. In Atmospheric Pollution 1980: Proceedings of the 14th International Colloquium, UNESCO Building, Paris, France, May 5-8, 1980 (pp. 37-42). Amsterdam, Netherlands: Elsevier Scientific Publishing Company.

Damak, M., \& Varanasi, K. K. (2018). Electrostatically driven fog collection using space charge injection. Science Advances, 4(6), eaao5323. DOI:10.1126/sciadv.aao5323

González Pedraza, O. J., Pacheco Ibarra, J. J., Rubio-Maya, C., Galván González, S. R., \& Rangel Arista, J. A. (2018). Numerical study of the drift and evaporation of water droplets cooled down by a forced stream of air. Applied Thermal Engineering, 142, 292-302. DOI:10.1016/j.applthermaleng.2018.07.011

Huff, F. A., Beebe, R. C., Jones, D. M. A., Morgan, G. M., Jr., \& Semonin, R. G. (1971). Effect of Cooling Tower Effluents on Atmospheric Conditions in Northeastern Illinois. Source: https://www.ideals.illinois.edu/bitstream/handle/2142/94436 /ISWSC-100.pdf?sequence $=1$

Kraemer, H. F., \& Johnstone, H. F. (1955). Collection of Aerosol Particles in Presence of Electrostatic Fields. Industrial \& Engineering Chemistry, 47(12), 2426-2434. DOI:10.1021/ie50552a020

Liao, J., Xie, X., Nemer, H., Claridge, D. E., \& Culp, C. H. (2019). A simplified methodology to optimize the cooling tower approach temperature control schedule in a cooling system. Energy Conversion and Management, 199, 111950. DOI:10.1016/j.enconman.2019.111950

Naik, B. K., \& Muthukumar, P. (2017). A novel approach for performance assessment of mechanical draft wet cooling towers. Applied Thermal Engineering, 121, 14-26. DOI:10.1016/j.applthermaleng.2017.04.042

Novianarenti, E., Setyono, G., \& Safitra, A. G. (2019). Experimental Study of The Performance Characteristic an Induced Draft Cooling Tower with Variates Fillings. IOP Conference Series: Materials Science and Engineering, 462, 012027. DOI:10.1088/1757-899x/462/1/012027

Parker, K. (2003). Electrical Operation of Electrostatic Precipitators (Energy Engineering). London, United Kingdom: The Institution of Engineering and Technology.

Perry, R. H., \& Green, D. W. (1997). Perry's Chemical Engineer's Handbook (8th ed.). Kansas, USA: McGraw-Hill Professional Pub.

Reznikov, M. (2003). Dielectrophoretic Dehumidification of Gas Stream in Low and Moderate Electrical Fields. Presented at the ESA-IEEE Joint Meeting of Electrostatics (pp. 230-240), Little Rock, AR, USA.

Reznikov, M. (2014). Electrically Enhanced Condensation I: Effects of Corona Discharge. IEEE Transactions on Industry Applications, 51(2), DOI:10.1109/tia.2014.2354734

Reznikov, M. (2015). Electrically Enhanced Harvesting of Water Vapor from The Air. Presented at the ESA Annual Meeting on Electrostatics.

Saber, H. A., \& Maree, I. E. (2019). Experimental study on thermal performance of counter flow wet cooling tower and effect of fins angle. Anbar Journal of Engineering Science, 8(1), 1-8. Source: https://www.iasj.net/iasj?func=fulltext\&aId=169264

Shublaq, M., \& Sleiti, A. K. (2020). Experimental analysis of water evaporation losses in cooling towers using filters. Applied Thermal Engineering, 175, 115418. DOI:10.1016/j.applthermaleng.2020.115418

Sundén, A. E. K., Støchkel, K., Panja, S., Kadhane, U., Hvelplund, P., Nielsen, S. B., ... Hansen, K. (2009). Heat capacities of freely evaporating charged water clusters. The Journal of Chemical Physics, 130(22), 224308. DOI:10.1063/1.3149784

Uchiyama, H., \& Jyumonji, M. (1995). Field experiments of an electrostatic fog-liquefier. Journal of Electrostatics, 35(1), 133-143. DOI:10.1016/0304-3886(95)00019-7

Veldhuizen, H., \& Ledbetter, J. (1971). Cooling Tower Fog: Control and Abatement. Journal of the Air Pollution Control Association, 21(1), 21-24. DOI:10.1080/00022470.1971.10469490

Wakil, M. M. E. (1985). Power Plant Technology (Rev. ed.). New York, St. Louis, San Francisco: Mc Graw-Hill Book Company.

Williamson, N., Behnia, M., \& Armfield, S. (2008). Comparison of a 2D axisymmetric CFD model of a natural draft wet cooling tower and a 1D model. International Journal of Heat and Mass Transfer, 51(9-10), 2227-2236. DOI: 10.1016/j.ijheatmasstransfer.2007.11.008

$\mathrm{Yu}, \mathrm{F}$. (2005). Modified Kelvin-Thomson equation considering ion-dipole interaction: Comparison with observed ionclustering enthalpies and entropies. The Journal of Chemical Physics, 122(8), 084503. DOI:10.1063/1.1845395 